\title{
Phenylketonuria: variable phenotypic outcomes of the R261Q mutation and maternal PKU in the offspring of a healthy homozygote
}

\author{
Sandra Kleiman, Lina Vanagaite, Jeanna Bernstein, Gerard Schwartz, Nathan Brand, \\ Avraham Elitzur, Savio L C Woo, Yosef Shiloh
}

\begin{abstract}
Phenylketonuria (PKU) and benign hyperphenylalaninaemia (HPA) result from a variety of mutations in the gene for the hepatic enzyme phenylalanine hydroxylase. PKU has been found in the Israeli population in two variants, classical and atypical. The two are clinically indistinguishable and require treatment with low phenylalanine diet to prevent mental retardation, but show differences in serum phenylalanine levels and in tolerance to this amino acid. Maternal PKU is a syndrome of congenital anomalies and mental retardation that appears in offspring of PKU mothers as a result of fetal exposure to the high phenylalanine level in the maternal blood. We studied a family in which two children with severe, classical PKU and their unaffected brother showed mild signs of maternal PKU. Their mother had no clinical signs of PKU, but the phenylalanine concentration in her serum reached a level that usually characterises PKU patients. This woman represents a rare phenotype, benign atypical PKU. Such 'hidden' PKU in women may lead to maternal PKU in the offspring, similar to overt PKU. Special attention should therefore be paid to women having children with any of the clinical hallmarks of maternal PKU, and to children born to women known to have benign HPA. The mother was also found to be homozygous for a missense mutation at the phenylalanine hydroxylase locus, R261Q, which does not abolish enzymatic activity completely. In two other families, homozygosity for this mutation resulted in atypical PKU in four children. This observation suggests that mutations that do not completely destroy phenylalanine hydroxylase activity may exhibit variable phenotypic expression which is unpredictable. Compound heterozygosity for R261Q and other mutations led in other patients either to classical PKU or to mild benign HPA.

( $f$ Med Genet 1993;30:284-8)
\end{abstract}

A raised serum phenylalanine level above $0.12 \mathrm{mmol} / 1$ is defined as hyperphenylalaninaemia (HPA), and results from impairment of phenylalanine hydroxylation to tyrosine in the liver. ${ }^{12}$ The defective enzyme in more than $98 \%$ of cases is phenylalanine hydroxylase (PAH), and the rest are explained by defects in the synthesis or metabolism of its cofactor, tetrahydrobiopterine. HPA with phenylalanine levels of $1.2 \mathrm{mmol} / 1$ or higher is usually expressed as the autosomal recessive disease phenylketonuria (PKU). PKU patients suffer from severe mental retardation unless diagnosed soon after birth and treated with a low phenylalanine diet throughout adolescence. Phenylalanine levels of 0.24 to $1.1 \mathrm{mmol} / 1$ are usually regarded as benign HPA and are not considered an indication for dietary treatment. The wide spectrum of HPAs has led to different designations for these conditions in different studies.

In Israel, a pioneer in establishing a national screening programme for HPA, ${ }^{3}$ two variants of PKU have been noted, which are clinically indistinguishable in the untreated state: severe classical PKU with serum phenylalanine levels of 1.2 to $4.8 \mathrm{mmol} / \mathrm{l}$ on a normal diet and phenylalanine tolerance of 200 to $500 \mathrm{mg}$ /day, and atypical PKU with serum phenylalanine of 1.2 to $2.4 \mathrm{mmol} / 1$ and a 500 to $1200 \mathrm{mg} /$ day tolerance. Less stringent dietary treatment is required in atypical PKU. (Previous communications referred to these variants of PKU as 'North European' and 'Mediterranean', ${ }^{45}$ reflecting the lack of common nomenclature.) Benign HPA (also termed 'non-PKU HPA'4) was classified in this population as 'high' or 'low', with serum phenylalanine levels of 0.6 to 1.08 and 0.24 to $0.72 \mathrm{mmol} / 1$ and phenylalanine tolerance of 1100 to 1700 and 1500 to $2000 \mathrm{mg} /$ day, respectively.

HPA variability reflects a wide spectrum of mutations at the PAH locus that reduce the enzyme activity to different extents. Over 30 such mutations have been identified since the cloning of the PAH gene, and the corresponding enzymatic defects have been correlated with the clinical-biochemical phenotypes associated with these mutations. ${ }^{67}$ The search for new mutations and the finding of known mutations in patients is facilitated by their association with specific haplotypes of restriction fragment length polymorphisms (RFLPs) in the PAH gene. ${ }^{6-11}$ During the last 25 years, routine screening of newborns for HPA and dietary treatment of PKU patients throughout childhood has resulted in increasing numbers of such patients who grow up and lead normal lives as adults without dietary restrictions. This success has been overshadowed, however, by the recent emergence of a new syndrome, maternal PKU, in women's children exposed in utero to high phenylalanine levels in their mother's blood. Maternal PKU is

\author{
Wedical Center Drive, \\ Received 5 August 1992. \\ Revised version accepted \\ 13 October 1992. \\ Dr Shiloh, Howard Hughes \\ Medical Institute Research \\ Laboratories, University of \\ Michigan Medical Center,
}


characterised by low birth weight, microcephaly, mental retardation, and a high risk of cardiac anomalies. ${ }^{1213}$ It can be avoided by reinstating the low phenylalanine diet before conception and throughout pregnancy. ${ }^{14}$ The growing awareness of the consequences of HPA during pregnancy has directed attention to females with benign HPA where high HPA not sufficient to cause overt PKU in the mother might nevertheless affect her fetus. ${ }^{15-17}$ Superti-Furga et $a l^{18}$ recently described a family in which mild PKU in two sisters resulted in maternal PKU in their offspring. Both sisters were homozygous for a missense mutation (R261Q) at codon 261 of the PAH gene, which does not totally abolish PAH enzymatic activity.

We present here genetic and molecular analyses of a family in which PKU and maternal PKU coexist in the offspring. The molecular basis for maternal PKU in this family is benign atypical PKU in the mother, who is homozygous for the R261Q mutation. Other phenotypes associated with this mutation in the Israeli population are presented.

\section{Patients and families}

Newborn screening in Israel and the criteria for classification of the different HPAs have been previously described. ${ }^{3-5}$ Psychological and developmental assessment of PKU patients is done on a yearly basis between the ages of 1 and 18 years using a variety of tests that examine IQ, motor-graphic ability, adaptation, educational achievement, and emotional development. The families investigated are part of a cohort of 110 Israeli families with HPA that recently underwent genetic and molecular analysis (Kleiman et al, in preparation).

\section{Methods}

For the molecular analysis, construction of RFLP haplotypes at the PAH gene and detection of previously recognised point mutations were as previously described. ${ }^{419}$

\section{Results}

GENETIC-MOLECULAR ANALYSIS OF A FAMILY WITH PKU AND MATERNAL PKU

In the family presented in fig 1 , two of the children are affected with classical PKU and are treated with a low phenylalanine diet. The parents are both of Palestinian Arab extrac-

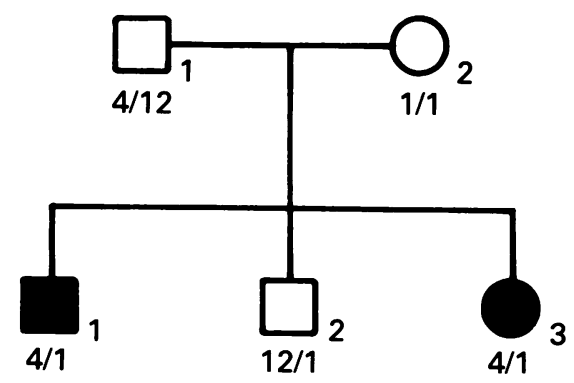

Figure 1 Pedigree of the family with PKU and maternal PKU. Numbers denote $P A H$ haplotypes according to Woo. ${ }^{20}$ tion, are healthy, and have no history of PKU or any other metabolic or genetic disorder in their families. Both grew up in middle class families with normal nutrition typical of this community. Physical examination showed all three children to be microcephalic (head circumference below the 2 nd centile). The IQ of the boy not affected with PKU (II-2) was 89, while that of his parents was 100 . Since these signs could be compatible with mild maternal PKU, serum phenylalanine level was tested in the mother and found to be $1.2 \mathrm{mmol}-1$. The high level was unusual, since most people with this degree of HPA are usually affected with PKU and show various degrees of mental retardation if not treated by diet. This woman was found, however, to be well adjusted socially and works as a school teacher. Her phenylalanine tolerance was $600 \mathrm{mg} /$ day. We therefore assigned a specific phenotype to this woman, benign atypical PKU. We concluded that the signs of mild maternal PKU found in the children resulted from maternal HPA.

Haplotype analysis showed the children with classical PKU in this family to be compound heterozygotes with mutant haplotypes 1 and $4,{ }^{20}$ while the mother was homozygous for haplotype 1 (fig 1). The patients were tested for the presence of the following mutations previously found to be associated with haplotypes 1 and 4 in other populations: R158Q, R243ter, R252W, R261Q, E280K, P281L, R408W, and Y414C..$^{6-921-25}$ Both patients were found to carry the missense mutation R261Q on one of their PAH alleles. This mutation changes an arginine residue into glutamine at codon 261 of the PAH gene and results in residual enzyme activity of $30 \% \cdot .^{21-2325}$ None of the other mutations was found in these patients. The presence of the R261Q mutation can be detected by PCR and subsequent HinfI digestion. Further investigation of the segregation of this mutation in the family showed, unexpectedly, that the mother was homozygous for this defect (fig 2). Direct sequencing of PCR products (not shown) confirmed the homozygosity of this woman for R261Q. The father's mutation is still unknown.

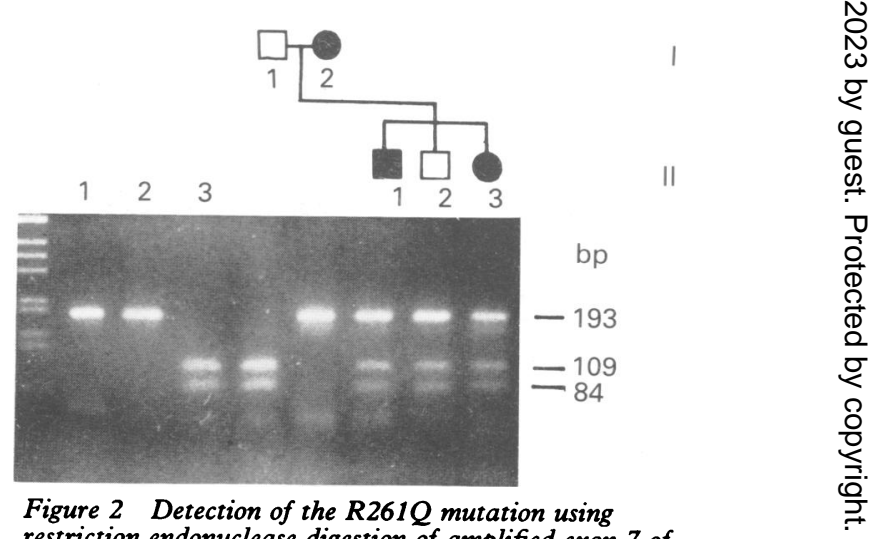
restriction endonuclease digestion of amplified exon 7 of the PAH gene. The mutation eliminates a HinfI site that divides the amplified fragment $(193 \mathrm{bp})$ into two portions of 109 and $84 \mathrm{bp}$. Lane 1: undigested PCR product. Lane 2: PCR product of an $R 261 Q$ homozygote, digested with HinfI. Lane 3: digested product from a normal homozygote. 
VARIABLE PHENOTYPES ASSOCIATED WITH THE R261Q MUTATION

In order to assess the involvement of the R261Q mutation in HPA in the Israeli population, the entire cohort of 110 HPA families (Kleiman et al, in preparation) was screened for the presence of this defect using PCR with HinfI digestion and sequencing in cases positive for this test. The mutation was detected in another five Palestinian Arab and Jewish families with different HPAs (table). It is noteworthy that in two Palestinian families, homozygosity for $R 261 Q$ resulted in the atypical variant of PKU requiring dietary treatment. Compound heterozygosity for R261Q and other mutations led either to classical PKU or to benign HPA. The R261Q mutation was associated with haplotype 1 in all but one family (table).

\section{Discussion}

The term HPA covers a broad spectrum of phenotypes differently designated in various studies. The mother in the family studied here exhibits a rare phenotype, with a phenylalanine level characteristic of PKU patients but with normal intelligence without dietary treatment. Subjects with high, untreated HPA and normal development have occasionally been noted in the past. ${ }^{126}$ While this phenotype indicates the ability of the central nervous system to cope with high HPA under certain undefined circumstances, the maternal PKU in our patient's children shows that the offspring of such subjects do not always escape the harmful effect of high maternal HPA.

The coexistence of classical PKU and maternal PKU in the same subjects was noted recently by Levy et $a l^{7}$ in a family in which the mother had overt, untreated, classical PKU. The maternal PKU in our family is less severe, however, than that usually observed in children born to PKU mothers. ${ }^{1213}$ In the family described by Superti-Furga et al, ${ }^{18}$ the two sisters had serum phenylalanine levels of 1.26 and $1.34 \mathrm{mmol} / \mathrm{l}$, low-normal intelligence, and more severe maternal PKU in their children than was seen in our patients. This correlation between the extent of maternal HPA and the severity of maternal PKU in the offspring has also been noted by others. ${ }^{28} 29$ It is noteworthy that the two PKU children in our family and their unaffected brother exhibited the same signs of maternal PKU, similar to the family reported by Levy et al. ${ }^{27}$ These findings indicate that phenylalanine hydroxylase activity in the normal fetus did not protect him against the excess phenylalanine in the maternal blood.

These observations indicate the possibility of mild cases of maternal PKU, primarily microcephaly, might be a sign to the paediatrician to examine serum phenylalanine in the mother. A finding of maternal HPA would imply a high risk for recurrence of this syndrome in subsequent offspring, and hence the necessity of dietary treatment during each pregnancy. Moreover, pregnancy outcomes should be systematically followed up in women previously diagnosed as having benign HPA. Similar concerns were recently expressed by other investigators. ${ }^{1529}$

The molecular basis of benign HPA in our family is of particular interest. The R261Q mutation has been previously identified in PKU patients, ${ }^{21} 22$ but seems to be variably expressed. We identified in our population two phenotypic outcomes of homozygosity for this mutation: atypical PKU which should be treated with diet to prevent mental retardation, and benign atypical PKU with normal intelligence under a normal diet. The sisters with high HPA and children affected with maternal PKU reported by Superti-Furga et $a l^{18}$ were also homozygous for the $\mathrm{R} 261 \mathrm{Q} \mathrm{mu}$ tation, with somewhat more pronounced phenotypic effects and more grave consequences in the children. Okano et $a l^{33}$ recently showed that in European populations subjects homozygous for R261Q exhibit a condition which, in our nomenclature, falls into the category of high benign HPA. This variable phenotypic expression might be the result of interaction with genetic and physiological factors of unknown nature. DiSilvestre et $a l^{30}$ described clinical differences between sibs with identical PAH haplotypes; although serum phenylalanine and phenylalanine tolerance were identical, PKU appeared in one sib and benign HPA

Association of the R261Q mutation with different HPAs.

\begin{tabular}{|c|c|c|c|c|c|c|}
\hline Patient & $\begin{array}{l}\text { Mutant } \\
\text { PAH } \\
\text { haplotypes }\end{array}$ & $\begin{array}{l}\text { PAH } \\
\text { mutations }\end{array}$ & $\begin{array}{l}\text { Ethnic origin } \\
\text { of } R 261 Q\end{array}$ & $\begin{array}{l}\text { Serum } \\
\text { phenylalanine } \\
(\mathrm{mmol} / \mathrm{l})^{*}\end{array}$ & $\begin{array}{l}\text { Phenylalanine } \\
\text { tolerance } \\
\text { (mg/day) }\end{array}$ & $\begin{array}{l}\text { Phenotypic } \\
\text { classification } \dagger\end{array}$ \\
\hline R261Q homozygotes & $\begin{array}{l}\text { sotes } \\
1 / 1\end{array}$ & R261Q/R261Q & Palestinian-Arab & $1 \cdot 2$ & 600 & \multirow{2}{*}{$\begin{array}{l}\text { Benign } \\
\text { atypical PKU } \\
\text { Atypical PKU } \\
\text { Atypical PKU } \\
\text { Atypical PKU } \\
\text { Atypical PKU }\end{array}$} \\
\hline \begin{tabular}{l|l} 
MW & sibs \\
VW & \\
SS & sibs \\
AS & sis
\end{tabular} & $\begin{array}{l}1 / 1 \\
1 / 1 \\
1 / 1 \\
1 / 1\end{array}$ & $\begin{array}{l}\text { R261Q/R261Q } \\
\text { R261Q/R261Q } \\
\text { R261Q/R261Q } \\
\text { R261Q/R261Q }\end{array}$ & $\begin{array}{l}\text { Palestinian-Arab } \\
\text { Palestinian-Arab } \\
\text { Palestinian-Arab } \\
\text { Palestinian-Arab }\end{array}$ & $\begin{array}{l}1.7 \\
1.8 \\
1.6 \\
1.9\end{array}$ & $\begin{array}{l}700 \\
800 \\
600 \\
600\end{array}$ & \\
\hline $\begin{array}{l}\text { R261Q compo } \\
\text { CL } \\
\text { MA\& } \\
\text { HAll } \\
\text { NH } \\
\text { YH } \\
\text { ZH } \\
\text { OF } \\
\text { KH sibs } \\
\text { MH }^{* *}\end{array}$ & $\begin{array}{l}\text { ad heterozygote } \\
1 / 2 \\
1 / 4 \\
1 / 4 \\
1 / 1 \\
1 / 1 \\
1 / 1 \\
28 / 10 \\
1 / 1 \\
1 / 1\end{array}$ & $\begin{array}{l}\mathrm{R} 261 \mathrm{Q} / \mathrm{R} 408 \mathrm{~W} \\
\mathrm{R} 261 \mathrm{Q} / ? \\
\mathrm{R} 261 \mathrm{Q} / ? \\
\mathrm{R} 261 \mathrm{Q} / ? \\
\mathrm{R} 261 \mathrm{Q} / ? \\
\mathrm{R} 261 \mathrm{Q} / ? \\
\mathrm{R} 261 \mathrm{Q} / ? \\
\mathrm{R} 261 \mathrm{Q} / ? \\
\mathrm{R} 261 \mathrm{Q} / \text { ? }\end{array}$ & $\begin{array}{l}\text { Jewish-Iraqi } \\
\text { Palestinian-Arab } \\
\text { Palestinian-Arab } \\
\text { Palestinian-Arab } \\
\text { Jewish-Iraqi } \\
\text { Jewish-Iraqi } \\
\text { Jewish-Iraqi } \\
\text { Jewish-Iraqi } \\
\text { Jewish-Iraqi }\end{array}$ & $\begin{array}{l}2.5 \\
2.2 \\
1.9 \\
2.5 \\
1.56 \\
1.38 \\
1.8 \\
0.48 \\
0.51\end{array}$ & $\begin{array}{r}300 \\
400 \\
400 \\
350 \\
350 \\
350 \\
300 \\
1600 \\
1700\end{array}$ & $\begin{array}{l}\text { Classical PKU } \\
\text { Classical PKU } \\
\text { Classical PKU } \\
\text { Classical PKU } \\
\text { Classical PKU } \\
\text { Classical PKU } \\
\text { Classical PKU } \\
\text { Mild benign HPA } \\
\text { Mild benign HPA }\end{array}$ \\
\hline
\end{tabular}

* Under normal diet. † See Avigad et al. ${ }^{4}$ In that paper classical PKU was termed 'the North European variant', atypical PKU was designated 'the Mediterranean variant', and benign HPA was termed 'non-PKU HPA'. $\ddagger$ I.2 in fig 1 . $\S I I \cdot 1$ in fig 1 . $\| I I \cdot 3$ in fig 1 . I Mother of $\mathrm{YH}$ and $\mathrm{ZH}$. ** Brother of $\mathrm{KH}$. 
in the other. The mutations responsible for these phenotypes were not reported. The phenotypic variability associated with certain PAH mutations is expected to present some difficulty when prenatal diagnosis of PKU is based on the identification of such mutations.

The variety of phenotypes associated with compound heterozygosity for R261Q and other mutations (table) has been noted by others, ${ }^{1021-232531}$ and is not surprising in view of the fact that it leaves a residual enzymatic activity of $30 \% .{ }^{23}$ However, even subjects with similar genotypes can show different phenotypes. Two patients with the R261Q/R408W genotype reported by Okano et $a l^{33}$ had serum phenylalanine levels of 1.26 and $1.02 \mathrm{mmol} / 1$ under normal diet, compared to $2.5 \mathrm{mmol} / 1$ in our patient with this genotype (table). Since the R408W mutation completely abolishes PAH activity, a residual enzymatic activity of $15 \%$ is expected in such a compound heterozygote. We would have expected high benign HPA or atypical PKU in such patients, but our patient shows classical PKU. Indeed, Okano et $a l^{23}$ noted that out of nine patients with expected residual PAH activity of $15 \%$, four showed a mild variant of PKU and five had classical PKU. These observations underline the importance of as yet undefined genetic and physiological factors affecting the final phenotypic outcome in PAH deficiencies.

It is noteworthy that in one of the JewishIraqi families, both classical PKU and mild benign HPA were associated with the R261Q mutation in different subjects (see $\mathrm{YH}, \mathrm{ZH}$, $\mathrm{KH}$, and $\mathrm{MH}$, table). We assume that the mutations associated with the other PAH allele in each of these phenotypes are different: a classical PKU mutation in the severely affected subjects, and a mutation with a milder effect on the enzyme in those affected with benign HPA. This genetic model for benign HPA has been extensively discussed in a previous communication from our laboratory. ${ }^{4}$

Haplotype 1 is associated with $50 \%$ of the mutant PAH alleles among Palestinian Arabs (Kleiman et al, in preparation). In this community eight of 36 mutant alleles with this haplotype carry the R261Q mutation, which is also usually associated with this haplotype in European and Mediterranean populations. ${ }^{6791021-23}$ Interestingly, a similar PAH allele bearing the same mutation and haplotype was found in five Jewish families of Iraqi origin. In another family from the same community, R261Q was associated with haplotype 28 (table). A rare association of this mutation with haplotype 28 was noted by Tyfield et al ${ }^{24}$ in south west England. The site of this mutation involves a CpG dinucleotide, a known hot spot for sequence variation, making the recurrence of this mutation ${ }^{832}$ a possibility. However, gene flow between different populations cannot be ruled out. We hope to resolve this question using additional sequence variations at the PAH locus.

We thank the staff of the Institute for Child Development at the Sheba Mecical Centre and the patients and their families for their co- operation. S L C Woo is an investigator at the Howard Hughes Medical Institute. This study was supported by the United States-Israel Binational Science Foundation.

1 Scriver CR, Kaufman S, Woo SLC. The hyperphenylalaninemias. In: Scriver CR, Beaudet AL, Sly WS, Valle $\mathrm{D}$, eds. The metabolic basis of inherited disease. 6 th ed. New York: McGraw-Hill, 1989:495-546.

2 Guttler $\mathrm{F}$, Lou $\mathrm{H}$. Phenylketonuria and hyperphenylalaninemia. In: Fernandes J, Saudubray JM, Tada K, eds. Inborn metabolic diseases - diagnosis and treatment. Berlin Springer, 1990:161-74.

3 Cohen BE, Szeinberg A, Levine T, et al. Phenylketonuria in Israel. Monogr Hum Genet 1978;9:95-101.

4 Avigad S, Kleiman S, Weinstein $M$, et al. Compound heterozygosity in non-PKU hyperphenylalaninemia: the contribution of mutations for classical PKU. Am ₹ Hum Genet 1991;48:393-9.

5 Shiloh Y, Avigad S, Kleiman S, et al. Molecular analysis of hyperphenylalaninemia in Israel: a study of Jewish genetic diversity. In: Bonne-Tamir B, Adam A, eds. Genetic diversity among fews: diseases and markers at the DNA diversity among fews: diseases and markers at the DNA

6 Eisensmith RC, Woo SLC. Phenylketonuria and the phenylalanine hydroxylase gene. Mol Biol Med 1991;8:318.

7 Konecki DS, Lichter-Konecki U. The phenylketonuria locus: current knowledge about alleles and mutations of the phenylalanine hydroxylase gene in various populations. Hum Genet 1991;87:377-88.

8 John SWM, Rozen R, Scriver CR, Laframbroise R, Laberge C. Recurrent mutation, gene conversion, or recombination at the human phenylalanine hydroxylase locus: evidence in French-Canadians and a catalog of mutations. Am f Hum Genet 1990;46:970-4.

9 Berthelon M, Caillaud C, Rey F, et al. Spectrum of phenylketonuria mutations in Western Europe and North Africa, and their relation to polymorphic DNA haploAfrica, and their relation to polymorphic DNA haplotypes at the phenyla

10 Dianzani I, Forrest SM, Camaschella C, Saglio G, Ponzone $A$, Cotton HG. Screening for mutations in the phenylalanine hydroxylase gene from patients with phenylketonuria by using the chemical cleavage method: a new splice mutation. Am f Hum Genet 1991;48:631-5.

11 Svensson E, von Dobeln U, Hagenfeldt L. Polymorphic DNA haplotypes at the phenylalanine hydroxylase locus and their relation to phenotype in Swedish phenylketonuria families. Hum Genet 1991;87:11-17.

12 Levy HL. Maternal phenylketonuria. Prog Clin Biol Res 1988;281:227-42.

13 Rouse B, Lockhart L, Matalon R, et al. Maternal phenylketonuria pregnancy outcome: a preliminary report of facial dysmorphology and major malformations. $\mathcal{f}$ Inher Metab Dis 1990;13:289-91.

14 Smith I, Glossop J, Beasley M. Fetal damage due to maternal phenylketonuria: effects of dietary treatment and maternal phenylalanine concentrations around the time of conception (an interim report from the UK Phenylketonuria Register). F Inher Metab Dis 1990; 13:651-7.

15 Luder ASW, Greene CL. Maternal phenylketonuria and hyperphenylalaninemia: implications for medical practice in the United States. Am $\mathcal{F}$ Obstet Gynecol 1989;161:11025 .

16 Hanley WB, Clarke TR, Schoonheyt WE. Undiagnosed phenylketonuria in adult women: a hidden public health

17 Waisbren SE, Levy HL. Effects of untreated maternal hyperphenylalanemia on the fetus: further study of families identified by routine cord blood screening. $₹$ Pediatr 1990;116:926-9.

18 Superti-Furga A, Steinmann B, Duc G, Gitzelman R. Maternal phenylketonuria syndrome in cousins caused by mild, unrecognized phenylketonuria in their mothers homozygous for the phenylalanine hydroxylase arg$261 \rightarrow \ln -261$ mutation. Eur $\exists$ Pediatr 1991;150:493-7.

19 Weinstein 1 . mutation, S349P, completely inactivates al A missense mutation, S349P, completely inactivates phenylalanine hydroxylase and is involved in different hyperphenylala

20 Wo SLC. Collation of RFLP haplotypes at the human phenylalanine hydroxylase (PAH) locus. Am $\mathfrak{\Im}$ Hum Genet phenylalanine hyd

21 Abadie V, Lyonnet S, Maurin N, et al. CpG dinucleotides are mutation hot spots in phenylketonuria. Genomics 1989;5:936-9.

22 Okano Y, Wang T, Eisensmith RC, Steinmann B, Gitzelmann R, Woo SLC. Missense mutations associated with RFLP haplotypes 1 and 4 of the human phenylalanine hydroxylase gene. Am f Hum Genet 1990;46:18-25.

23 Okano Y, Eisensmith RC, Guttler F, et al. Molecular basis of phenotypic heterogeneity in PKU. $N$ Engl $\mathcal{J}$ Med 1991;324:1232-8.

24 Tyfieid LA, Osborn MJ, Holton JB. Molecular heterogeneity at the phenylalanine hydroxylase locus in the population of the South-west of England. 7 Med Genet 1991;28:244-7.

25 Okano Y, Wang T, Eisensmith RC, et al. Phenylketonuria missense mutations in the Mediterranean. Genomics 1991;9:96-103. 
26 Primrose DA. Phenylketonuria with normal intelligence. $\mathfrak{f}$ Ment Defic Res 1983;27:239-41.

27 Levy HL, Lobbregt D, Sansaricg C, Snyderman SE. Comparison of phenylketonuric and nonphenylketonuric siblings from untreated preganancies in a mother with phenylketonuria. Am $\mathcal{F}$ Hum Genet 1992;44:439-42.

28 Levy HL, Waisbren SE. Effects of untreated maternal phenylketonuria and hyperphenylalaninemia on the fetus. N Engl f Med 1983;309:1269-74.

29 Hanley WB, Clarke JTR, Schoonkeyt W. Maternal phenylketonuria (PKU) - a review. Clin Biochem 1987;20:149 58.
30 DiSilvestre D, Koch R, Groffen J. Different clinical manifestations of hyperphenylalaninemia in three siblings with identical phenylalanine hydroxylase genes. Am $\mathcal{f}$ Hum Genet 1991;48:1014-6.

31 Tyfield LA, Meredith AL, Osborn MJ, et al. Genetic analysis of treated and untreated phenylketonuria in one family. $\mathcal{F}$ Med Genet 1990;27:564-8.

32 Okano Y, Wang T, Eisensmith RC, Guttler F, Woo SLC. Recurrent mutation in the human phenylalanine hydroxylase gene. Am f Hum Genet 1990;46:919-24. 